\title{
Development of Digital Signage for Primary School using Raspberry Pi
}

\section{Teddy Surya Gunawan', Arjuna Ginting ${ }^{2}$, Ahmad Syukri Md Sharif ${ }^{3}$, Nur Anzelina Harahap ${ }^{4}$, Ali Sophian ${ }^{5}$, Ramadhanu Ginting ${ }^{6}$}

${ }^{1}$ ECE Department, IIUM,Malaysia

${ }^{1}$ FTIK, UniversitasPotensi Utama, Indonesia

${ }^{2,4,6}$ Fakultas Teknik dan IlmuKomputer, UniversitasPotensi Utama, Medan, Indonesia

${ }^{3}$ Electrical and Computer Eng. Department, International Islamic University Malaysia, Kuala Lumpur, Malaysia

${ }^{5}$ Mechatronics Engineering Department, International Islamic University Malaysia, Kuala Lumpur, Malaysia

tsgunawan@iium.edu.my11, tsgunawan@potensi-utama.ac.id ${ }^{1}$, arjunagintingsuka87@gmail.com²,

asms.haramain.313@gmail.com ${ }^{3}$, nuranzelinahrp22@gmail.com ${ }^{4}$, ali_sophian@iium.edu.my ${ }^{5}$,

kedanzr2@gmail.com ${ }^{6}$

Article History: Received: 10 November 2020; Revised: 12 January 2021; Accepted: 27January 2021;

Published online: 05April 2021

\begin{abstract}
Nowadays, digital signage is a modern advertisement alternative that took over billboards and other traditional advertisements. In the context of education, digital signage provides students, teachers, and parents with an effective way of communication. This research proposed designing and developing low-cost digital signage using Raspberry Pi to be stationed at primary school. An LCD monitor and Raspberry Pi 4 single-board computer were utilized to display various informative content, such as examination date, daily schedule, and other announcements. Two methods were proposed, including Screenly and WordPress on a web server. The WordPress version needs to install PHP, MySQL, and Nginx web server, which can be accessed and updated remotely. Results showed that the free version of Screenly would be adequate for a simple announcement, but the developed WordPress version will be more appropriate and flexible for the primary school purpose.

Keywords: WordPress, Content Management System, Web server, Digital Signage, Raspberry Pi.
\end{abstract}

\section{Introduction}

There has been growing interest in the use of digital signage to replace traditional static signage. Digital signage can be dynamic and can be easily updated according to the advertiser's need. There is much information in primary school that needs to be displayed repetitively, such as examination date, daily schedule, and other important announcements. Digital signage provides a way to improve the communication process between students, teachers, and parents. However, commercial digital signage is often expensive, and many primary schools cannot afford it.

In 2006, the low-cost Raspberry Pi was developed to spur interest in programming [1, 2]. Its low cost but enough computational capability provides an excellent choice for developing low-cost digital signage. Previously, traditional signage has been placed in various strategic locations [3]. However, digital signages are rampantly increasing in a familiar place, so natural, that most people consume them without intending [4, 5]. A readily available gadget could be transformed into a smart web-based device [4], using container technology [5], and sometimes with an enormous LED TV size for marketing and advertising [6]. Digital signage was used to convey content in commercial, informational, experiential, and behavioral manifestation. The benefits of using digital signage are apparent, including cheaper operational costs, higher update rates, and newer media usages, such as animations and videos that offer interactive content for prospective clients.

Digital signage is not like standard over-the-air broadcast television. Instead, modern-day digital signage typically depends on more than one audio, video, or data file delivered concurrently to a single screen for simultaneous display, which can offer real-time or near real-time information. Content delivered by digital signage has expanded and proliferated, as stated in [6]. The content can now be displayed in multiple parts of the same screen.

A specially designed digital signage software allows the client to deal with all the data using remote access [79]. The control panel typically will be designed to be accessible in the multi-operating system environment, such as Windows, Mac OS, or Linux, using a simple web browser for remote access $[10,11]$. The LCD screen can show multiple information, which can be updated based on time of day, location, and priority.

In primary school, students may tell their parents or guardian about what happens at school. However, it has the tendency to under-communicate with their parent regarding vital information that their parent supposed to know. For example, actual examination dates, parent-teacher meetings, daily class schedule, report card day, and 
sports day. Digital signage outside the school can keep those parents updated. This paper aims to develop low-cost digital signage using Raspberry $\mathrm{Pi}$, which can be updated quickly and remotely. Raspberry Pi is utilized as an additional device attached to an LCD monitor placed strategically across the school.

\section{Prototype Design of Digital Signature}

Digital signage is different in terms of its capability to give what types of output. As in familiar places around the city, the advertisements displayed were news, videos, and pictures. There must be a computer or media player that can play or display the contents. This section discussed the design of the proposed digital signature, including its hardware and software design.

\section{A. Hardware Design}

Fig. 1 shows the proposed digital signage system with its implementation. The system outlined consists of a single client system and several server systems.

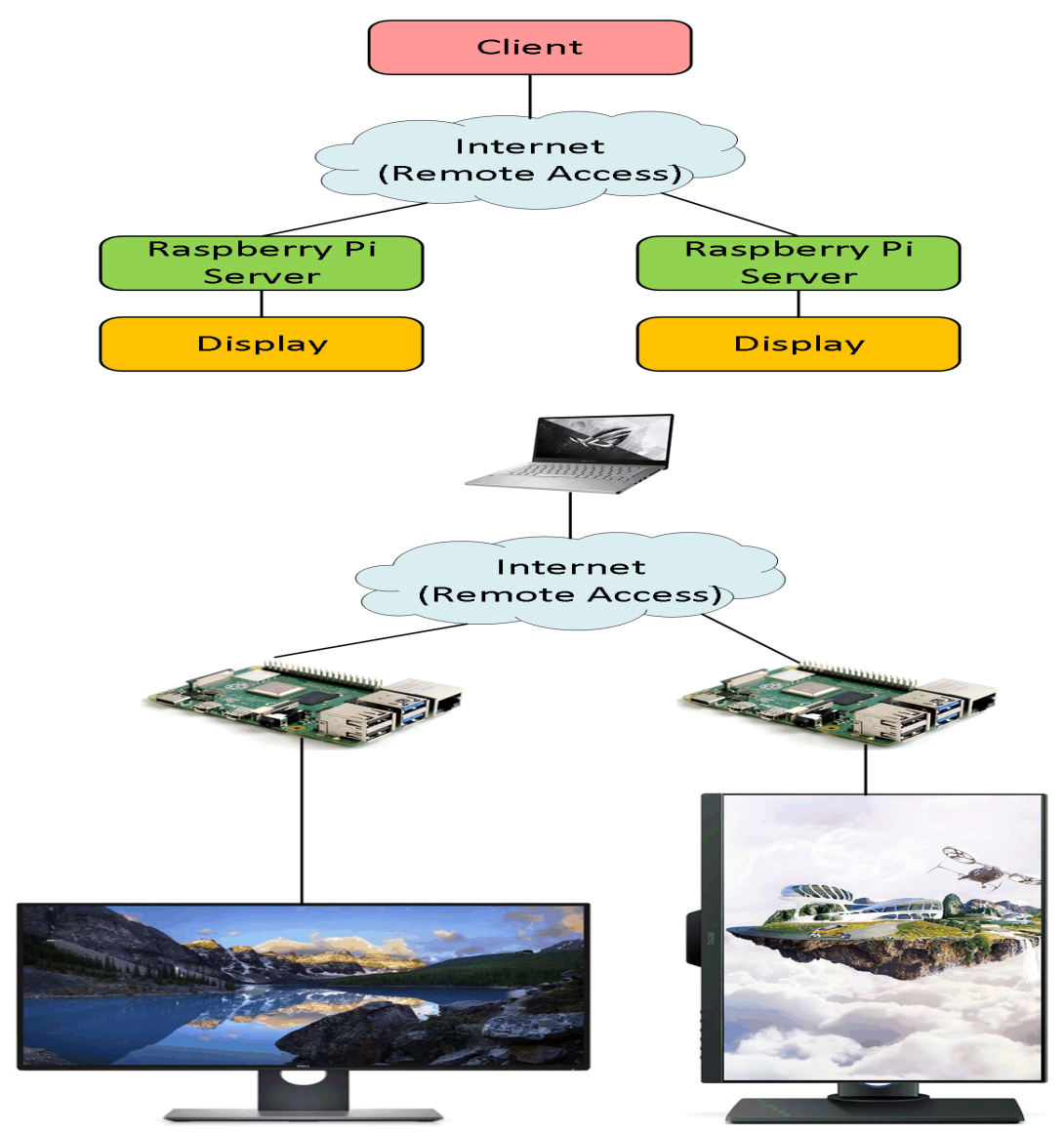

Figure 1.Digital Signage System Design and Implementation

The server implemented in this project is Raspberry Pi 4, configured adequately as a server with all the necessary software. In general, the client will communicate with the server system, reading the client requests, and displaying the necessary information. The server can independently work when there is no internet connection available, but it just works based on the client's last request or last update. The client, on the other hand, will initiate the request to the server. As shown in Fig. 1, the LCD monitor can be in landscape or portrait mode depending on the user requirements to maximize the information displayed. The LCD monitor is connected to Raspberry Pi 4 using an HDMI port, placed at the wall outside the school, as shown in Fig. 2. 


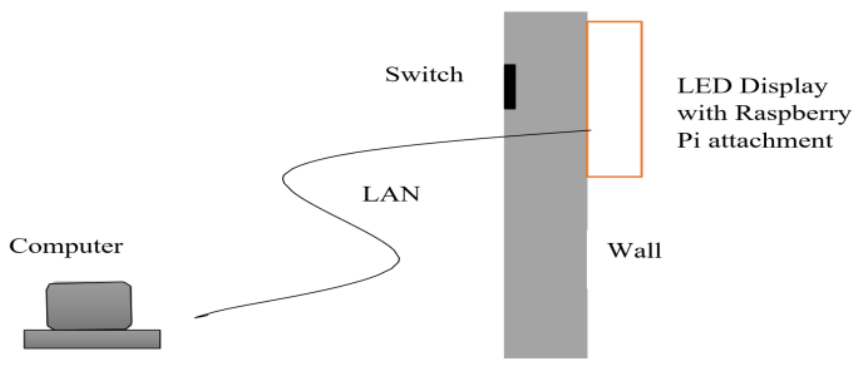

Figure 2.System Implementation

\section{B. Software Design}

In this paper, two software designs are proposed, including digital signage based on commercial software or developed content management system (CMS), i.e., WordPress, on a web server. A digital signage software solution connects all components, associating the hardware and the input content, thus allowing users or clients to manage the display and update their digital media remotely. Many commercial and open-source software are available, including Screenly, Rise vision, Concerto, Info-Beamer, TellyStream, Pi Present, and Xibo. In our evaluation, Screenly was found to be suitable and easy to use compared to the other solutions. Fig. 3 shows the Screenly scheduled overview screenshot. Of course, the free version has many limitations compared to the paid version.

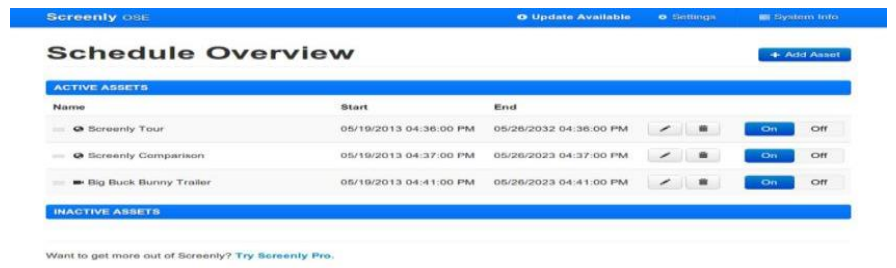

Figure 3.Screenly Schedule Overview Screenshot

The second software design was to use WordPress as a content management system (CMS). All the necessary information will be uploaded to the system, for example, the pictures and posters of various school events. PHP, MySQL, and Nginx web server were installed on the Raspberry Pi 4 with a specific command, i.e., sudo apt-get install nginxmysql-server php5-fpm php5-mysql. The user can remotely connect to Raspberry Pi to update the necessary information. Fig. 4 shows the flowchart of the digital signage system, while the WordPress admin page screenshot is shown in Fig. 5

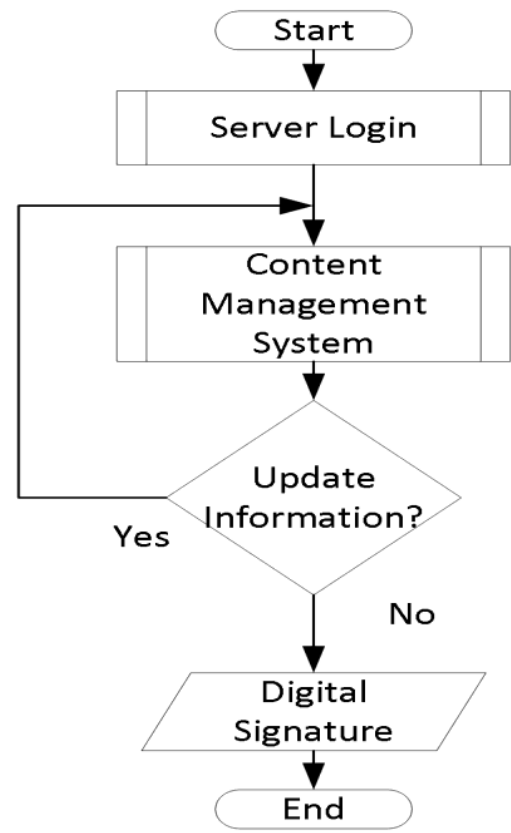

Figure 4.Flowchart of digital signage 


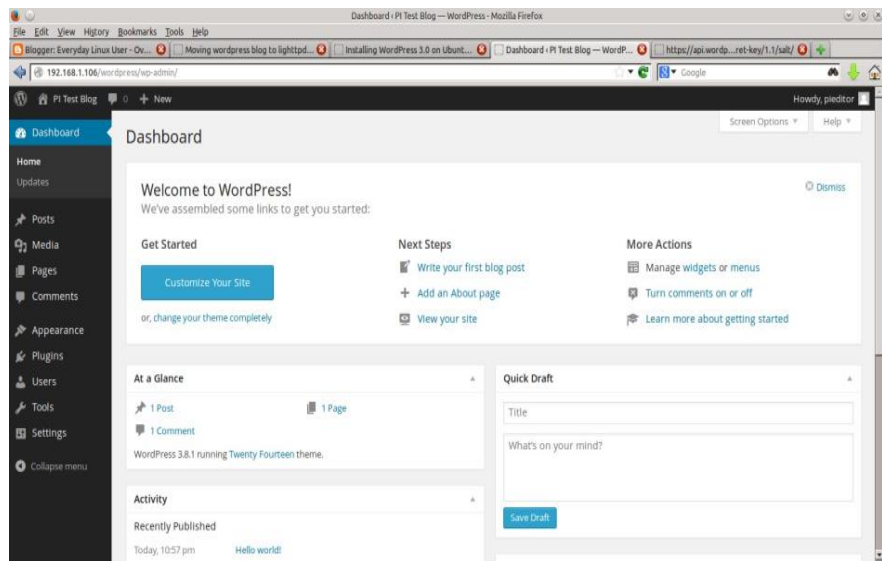

Figure 5.WordPress Admin Page Screenshot

The digital signage management interface allows the teacher or staff to customize their web advertising over any device that can access the Internet. This design brings practical solutions to the digital signage application. Simple web browsers can act as a digital advertising panel.

\section{Results and Discussion}

This section elaborates on two software design results mentioned in the previous section, namely, Screenly and WordPress. Our prototype was implemented and tested at SekolahBerasramaPenuhIntegrasi Gombak (Gombak Integrated Fully Residential School).

\section{A. Experiment on Digital Signage using Screenly}

Screenly was the first method we had used to implement digital signage. The Screenly will autorun at boot, and that viewer should start automatically with $\mathrm{X}$, as shown in Fig. 6. Presently, Screenly can display videos, images, and web pages.

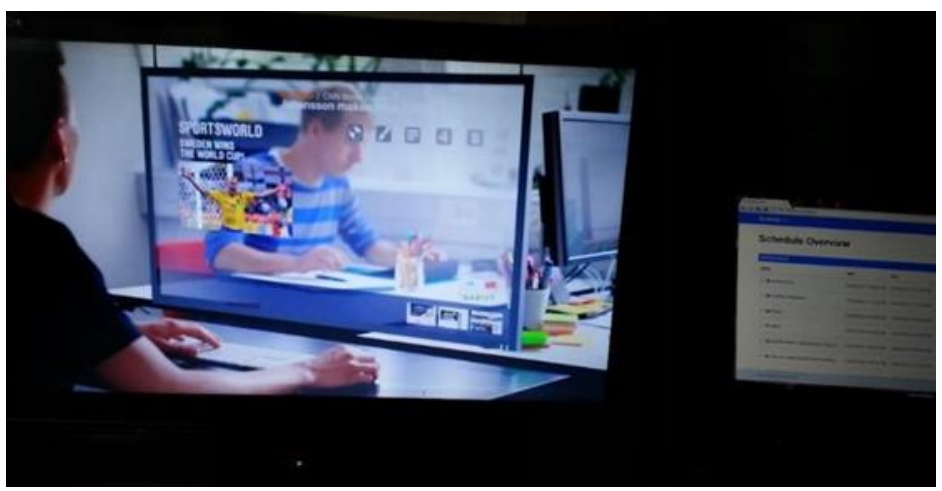

Figure 6.Sample of Video Advertisement using Screenly

Screenly works well with the randomly looping image at 5 seconds (by default) time duration for each image. Interestingly, we could also set the timer manually and make the images loop in sequence order. As for video performance, Screenly supported h264-coded files that can be played using the default media player with good audio. However, the free version supports $500 \mathrm{MB}$ storage only.

Another limitation of using the free version of Screenly is that the screen cannot support multiple information. Only one information is allowed per screen region. However, it still displays pictures, videos, and webpages rotated based on the schedule. The display plays statically, no fancy animation and crawler line at the bottom page, and no weather and date feed widget. Besides, due to its active development, we need to update it frequently to fix some bugs. Nevertheless, Screenly will be adequate for a simple announcement. 


\section{B. Experiment on Digital Signage using WordPress}

WordPress on a webserver was the second method we used. We uploaded the contents to the CMS and hosted it to Raspberry to display it to the LCD monitor by opening the built-in web browser. Fig. 7 shows the result of our WordPress implementation. WordPress has been known to be stable and simple to update and to manage. It can be customized with thousands of plugins with just a few codes.

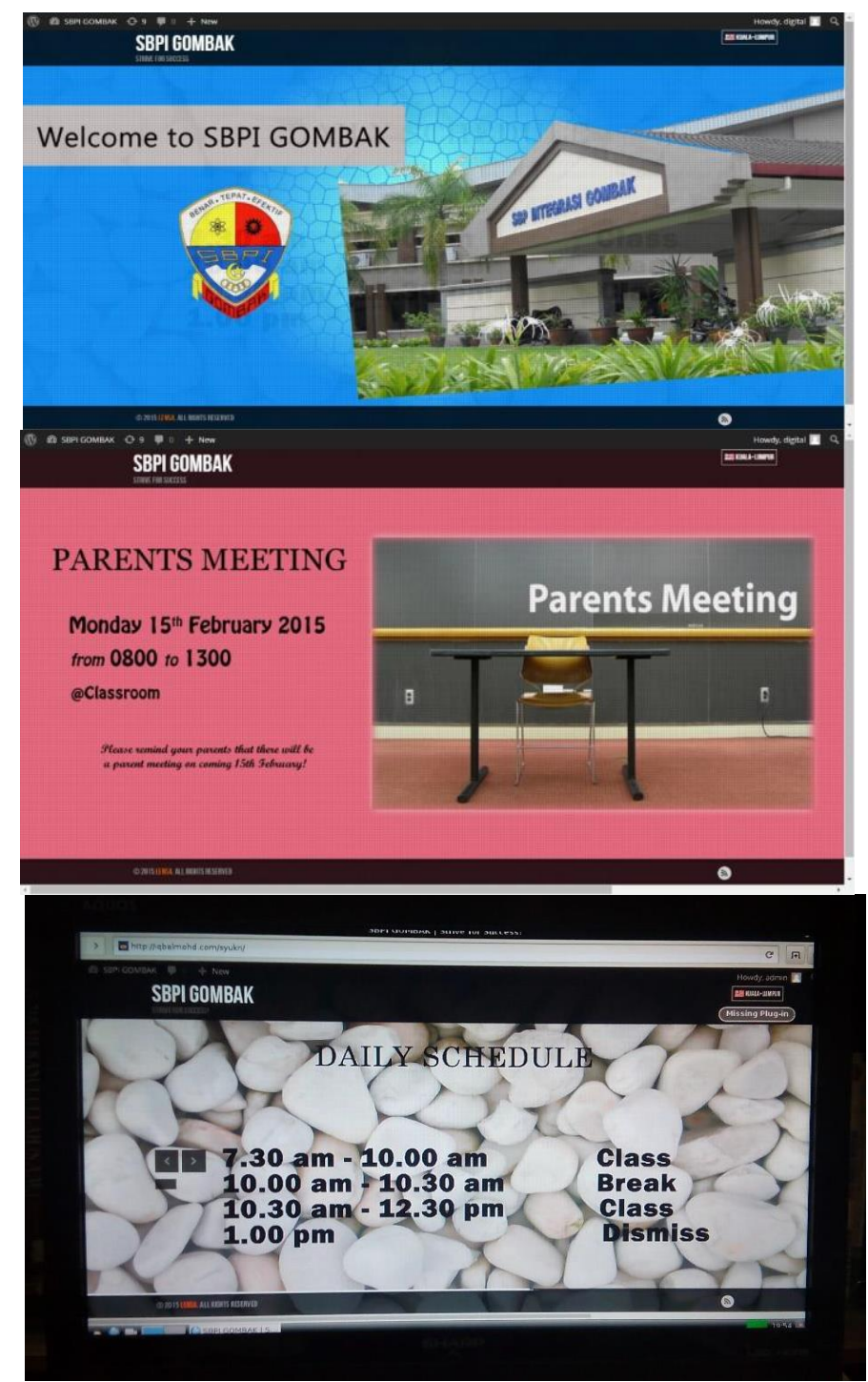

Figure 7.Sample of Digital Signage Screenshot on WordPress

Easy to customize the content is our main concern as we would manage the webserver anywhere and anytime using other remote devices. It also supports various information to be inserted in a webpage such as media (image and video), plugin, RSS feed, and others, which brings the display to become dynamic and attractive. Moreover, Raspberry Pi 4 provides enough processing power for a fast and smooth transition between information.

\section{Conclusions and Future Works}

This paper has presented the design and development of low-cost digital signage for primary school SekolahBerasramaPenuhIntegrasi Gombak (Gombak Integrated Fully Residential School). Raspberry Pi 4 was selected due to enough processing power for digital signage applications. Two methods were implemented in our experiments, including Screenly and WordPress on a web server. Experimental results showed that the first method is sufficient for simple announcements, while the second method is more suitable for primary school needs. Further research includes using other advanced CMS, implementing face recognition to tailor the information based on the predictive age, and hardening the digital signage security. 


\section{Acknowledgment}

We would like to extend our gratitude for the support from International Islamic University Malaysia and UniversitasPotensi Utama for providing funding and facilities for this research.

\section{References}

1. C. Edwards, "Not-so-humble raspberry pi gets big ideas," Engineering \& Technology, vol. 8, no. 3, pp. 30-33, 2013.

2. T. S. Gunawan, M. H. H. Gani, F. D. A. Rahman, and M. Kartiwi, "Development of face recognition on raspberry pi for security enhancement of smart home system," Indonesian Journal of Electrical Engineering and Informatics (IJEEI), vol. 5, no. 4, pp. 317-325, 2017.

3. . Strohbach and M. Martin, "Toward a platform for pervasive display applications in retail environments," IEEE Pervasive Computing, vol. 10, no. 2, pp. 19-27, 2011.

4. R. Want and B. N. Schilit, "Interactive digital signage," Computer, vol. 45, no. 5, pp. 21-24, 2012.

5. Y. Park, H. Yang, T. Dinh, and Y. Kim, "Design and implementation of a container-based virtual client architecture for interactive digital signage systems," International Journal of Distributed Sensor Networks, vol. 13, no. 7, p. 1550147717717864, 2017.

6. C. Bauer, P. Dohmen, and C. Strauss, "Interactive digital signage-an innovative service and its future strategies," in 2011 International Conference on Emerging Intelligent Data and Web Technologies, 2011: IEEE, pp. 137-142.

7. J. Schaeffler, Digital signage: software, networks, advertising, and displays: a primer for understanding the

8. T. S. Gunawan et al., "Prototype design of smart home system using internet of things," Indonesian Journal of Electrical Engineering and Computer Science, vol. 7, no. 1, pp. 107-115, 2017.

9. T. S. Gunawan, I. R. H. Yaldi, M. Kartiwi, and H. Mansor, "Performance evaluation of smart home system using internet of things," International Journal of Electrical and Computer Engineering, vol. 8, no. 1, p. 400, 2018.

10. K.-c. Yin, H.-c. Wang, D.-1. Yang, and J. Wu, "A study on the effectiveness of digital signage advertisement," in 2012 International Symposium on Computer, Consumer and Control, 2012: IEEE, pp. 169-172.

11. J. Y. Lee, M. S. Kim, D. W. Seo, C.-W. Lee, J. S. Kim, and S. M. Lee, "Dual interactions between multidisplay and smartphone for collaborative design and sharing," in 2011 IEEE Virtual Reality Conference, 2011: IEEE, pp. 221-222. 